\title{
Safer Sex as the Bolder Choice: Testosterone Is Positively Correlated with Safer Sex Behaviorally Relevant Attitudes in Young Men
}

Sari M. van Anders, PhD, ${ }^{*}$ Katherine L. Goldey, BA, ${ }^{\dagger}$ Terri D. Conley, PhD, ${ }^{*}$ Daniel J. Snipes, BA, ${ }^{\ddagger}$ and Divya A. Patel, PhD

*Departments of Psychology \& Women's Studies, University of Michigan, Ann Arbor, MI, USA; 'Department of Psychology, University of Michigan, Ann Arbor, MI, USA; ҒDepartment of Psychology, California State University, Long Beach, Long Beach, CA, USA; \$Department of Obstetrics, Gynecology and Reproductive Sciences, Yale University School of Medicine, New Haven, CT, USA

DOI: $10.1111 /$ j.1743-6109.2011.02544.x

\section{A B S T R A C T}

Introduction. Higher testosterone ( $\mathrm{T}$ ) is tied to risk-taking, especially in financial domains but also in health domains relevant to acquiring sexually transmitted infections (STIs). However, safer sex constructs could themselves carry the possibility of "social risk" due to sexual stigma or embarrassment, or could involve boldness or confidence because they could represent status displays of frequent sexual activity.

Aim. To determine how $\mathrm{T}$ and behaviorally relevant attitudes about sexual risk-taking are linked, to better understand biopsychosocial aspects of sexual health related to STIs.

Methods. In 78 first-year male college students, we examined correlations between salivary $\mathrm{T}$ and behaviorally relevant safer sex attitudes assessed via questionnaires.

Main Outcome Measures. T, via saliva; safer sex attitudes, via a composite and the University of California, Los Angeles Multidimensional Condom Attitudes Scale (MCAS).

Results. Higher T was significantly correlated with higher scores on the following: safer sex likelihood composite, $r(73)=0.33, P=0.003$; the MCAS safer sex resilience, $r(32)=0.36, P=0.037$; and the MCAS condom purchase comfort, $r(32)=0.37, P=0.031$. Associations between $\mathrm{T}$ and safer sex likelihood and resilience were still robust after controlling for potential confounds, though the association between $\mathrm{T}$ and purchase comfort diminished to a trend.

Conclusions. Higher T was positively linked with safer sex attitudes, especially those most closely tied to STI risk avoidance. Thus, future research and interventions for STI prevention should address the possibility that safer sex may be paradoxically perceived as a "bold" or "risky" choice even as it decreases STI risk. van Anders SM, Goldey KL, Conley TD, Snipes DJ, and Patel DA. Safer sex as the bolder choice: Testosterone is positively correlated with safer sex behaviorally relevant attitudes in young men. J Sex Med 2012;9:727-734.

Key Words. Testosterone; Attitudes; Behavior; Sexuality; Risk-Taking; Condom; Safer Sex; Sexually Transmitted Infections

\section{Introduction}

$\mathrm{R}$ esearch on endocrine correlates of risk-taking is usually conducted outside of health-related domains, except for a small body of studies related to sexual health. Most of these studies focus on the hormone testosterone ( $\mathrm{T}$ ) and behaviors conceptualized as risky because they are known to lead to higher incidences of sexually transmitted infections (STIs) [1-3]. Accordingly, studies have documented associations between higher $\mathrm{T}$ and more substance use, sexual partners, sexual activity, and permissive attitudes about sexuality [4-9]. Though there is evidence that social behaviors seem to affect $\mathrm{T}$ more strongly than $\mathrm{T}$ predicts behaviors [10], directionality of effect is unclear as evidence 
also supports bidirectional associations [11]. Together, these literatures highlight the importance of biopsychosocial approaches to risk-taking for developing a comprehensive and nuanced account of sexual health.

"Risk" is a complex issue in sexual health because sexuality holds varied, and sometimes contrasting, sexual norms. On one hand, any sexual behavior might be perceived as socially risky due to stigma, even those that promote safety. For example, individuals who ask for or use condoms are often judged as unsafe or untrusting [12-14] especially in long-term relationships [15], which can ironically place individuals who are proactive about safer sex at social risk in terms of relationships, reputation, or social status $[14,16,17]$. And, embarrassment is a major reason why younger and older adults avoid purchasing condoms [18]. In these cases, safer sex behaviors become the "socially risky" choice because of their social or emotional ramifications. On the other hand, men who engage in more frequent sexual activity are afforded more social status [19], and safer sex behaviors such as purchasing and possessing condoms could be one way that such status is expressed or enacted, especially as individuals with more partners report less embarrassment purchasing condoms [20]. In this case, safer sex behaviors become the bold or confident choice because they signify status. Relevant to both cases, confidence and assertiveness have been seen as key features of condom use $[4,21,22]$. In sexual health domains, then, safer sex behaviors may be linked to higher $T$ because they are the bolder choice and either carry social risk or convey social status, especially given that confidence and expressions of power have been tied to higher $\mathrm{T}$ [23].

The majority of research on $\mathrm{T}$ and risk-taking has focused not on health but instead on financial or more general risks, with findings generally linking higher $\mathrm{T}$ and more risk-taking [24-29], with some mixed findings [30-34]. Though the mechanisms supporting these associations are unclear, studies have demonstrated associations between higher $\mathrm{T}$ and psychological constructs relevant to risk-taking, such as confidence [35], status displays $[23,28]$, sensation-seeking [36-38], boredom susceptibility [38], lower startle responsivity, and thus potentially reduced fear responses to aversive stimuli [39], and higher sensitivity to reward in gambling tasks rather than punishment [40]. Moreover, individuals with a lower capacity for $\mathrm{T}$ to bind to androgen receptors also report higher anxiety, suggesting that higher levels of functional $\mathrm{T}$ are linked with less worry [41]. As such, it may not be risk-taking per se that is linked with higher $\mathrm{T}$, but the bold confidence or status underlying many of its enactments. Thus, even "safe" choices might be socially risky when they expose individuals to social opprobrium or confer status and thus require boldness or confidence.

In this study, we investigated whether $\mathrm{T}$ was associated with individual variation in behaviorally relevant attitudes about sexual risk-taking, adding to past research that used broadly defined risk factors by focusing on attitudes and behaviors directly related to STIs. We conducted these analyses with a sample of men recruited during their first year of college, which is an ideal time to address this question. Individuals have received some degree of sexual education, have typically begun embarking upon their sexual lives, and are generally experiencing newfound freedom from home constraints and established peer relationships. In addition, there is a circumscribed social group with developing friendships and intimate contacts, such that reputation development and maintenance can be meaningful influences on attitudes and behavior. Moreover, STIs and sexual risk behaviors are prevalent at this age $[42,43]$.

\section{Aims}

Our aim in this study was to investigate whether levels of $\mathrm{T}$ were associated with individual variation in behaviorally relevant safer sex attitudes and their converse, attitudes about sexual risk-taking, to better understand biopsychosocial aspects of sexual health related to STIs.

\section{Methods}

\section{Participants}

Participants were university first-year students recruited for the Implications of Partnerships Around the College Transition (ImPACT) study, a study examining associations between hormonal, health, social, and sexual variables during the first year of college. We analyzed data from the 78 men (mean age $=18.17$ years, standard deviation $[\mathrm{SD}]=0.61$ years) who participated in the baseline study session. This sample included 17 Asian, two black/African American, two Hispanic/Latino, four multiracial, and 52 white participants. The majority of the participants had lived in the United States for their entire lives (74\%), had parents who attended college (94\%), and came from family 
background with incomes above \$75,000/year (70\%). Eight participants were employed in addition to their student status. The participants selfidentified their sexual orientation, and 94\% identified as heterosexual, with three bisexual responders. No participants reported use of medications or the presence of health conditions that affect $\mathrm{T}$. They were a relatively sexually inexperienced group, with $46 \%$ reporting ever engaging in sexual intercourse (vaginal or anal) and $78 \%$ not engaging in partnered sexual activity over the past week. Given that the participants were first-year college students, i.e., had passed standardized tests of cognitive abilities and achieved grade points above specific cutoffs to earn entry, we were confident that the students were capable of understanding the questionnaires.

\section{Materials}

\section{Questionnaires}

Health and Demographics. This questionnaire included items such as race/ethnicity and age to describe the sample, items pertaining to control variables (e.g., height and weight to calculate body mass index), and items about potential confounds with $\mathrm{T}$ (e.g., medication use).

Safer Sex Likelihood. We created a safer sex likelihood composite from three items that are strongly related to STI incidence and protection [44-48], each rated on a five-point semantic differential scale: likelihood of practicing safer sex (actual mean score $=4.45, \mathrm{SD}=0.98$ ), how informed one is about human immunodeficiency virus $(\mathrm{HIV}) / \mathrm{STIs}$ (actual mean score $=4.65, \mathrm{SD}=0.58$ ), and (reverse-coded) frequency of one-night stands (actual mean score $=4.51, \quad \mathrm{SD}=0.92$ ). The minimum possible total score was 3 , while the maximum was 15 ; high scores thus represented a higher likelihood of safer sex. The participants' actual scores ranged from 9 to $15(M=13.62$, $\mathrm{SD}=1.58)$.

University of California, Los Angeles Multidimensional Condom Attitudes Scale (MCAS). The MCAS $[13,49]$ addresses various parameters of condom use and attitudes. We focused on the safer sex resilience subscale (originally labeled action maintenance) because it evaluates participants' likelihood to use condoms in the face of obstacles and has been shown to be particularly relevant to condom use behavior, and more so than the other measures [13].

The participants indicate their responses on a scale ranging from " 1 " = "I strongly disagree" to
"7" = "I strongly agree." We used the shortened 16-item version [13]. There are six subscales: (i) safer sex resilience (originally named action maintenance) measures the likelihood to use condoms in the face of obstacles (e.g., "I will be careful and play it safe with a condom even in the heat of the moment") and has been shown to be particularly relevant to condom use behavior [13]; (ii) effectiveness (e.g., "I think condoms are an effective method of preventing AIDS"); (iii) pleasure (e.g., "Condoms can be erotic for me"); (iv) identity stigma (e.g., "My partner will think I do not trust him/her if I suggest using a condom"); (v) purchase comfort (e.g., "I feel uncomfortable when I buy condoms," reverse coded); and (vi) negotiation (e.g., "I am comfortable talking about condoms with my partner"). Scores are summed such that higher scores always indicate more positive attitudes toward condoms. Consistent with previous studies [13], we limited our MCAS analyses to participants who had ever engaged in sexual intercourse; items would otherwise be irrelevant.

Relationships and Sexuality. The participants selfidentified their relationship status based on definitions we provided (see [50]), and we categorized participants as single (not involved with anyone, $\mathrm{N}=37$ ), casually partnered (with one or more noncommitted dating or sexual encounter partners, $\mathrm{N}=11$ ), or in a committed relationship $(\mathrm{N}=27)$. The participants also indicated if they had ever been sexually active, and if so, which sexual behaviors they had engaged in (e.g., oral, vaginal, anal). The participants also indicated how frequently they had engaged in sexual activity over the past week.

Saliva Samples. We measured $\mathrm{T}$ using saliva samples, which are minimally invasive and widely used for psychological studies. Salivary $T$ assays are well-validated, and salivary $\mathrm{T}$ shows high correlations with free serum $\mathrm{T}$ [51-53] and total serum $T[54,55]$. Salivary $T$ is considered to reflect the fraction of $\mathrm{T}$ that is "bioavailable," i.e., not bound or weakly bound to binding proteins and available to bind with receptors [56].

The participants provided a saliva sample by passive drool into a $17-\mathrm{mL}$ polystyrene tube. Samples were frozen until assay at the university's core assay facility. Samples were radioimmunoassayed using commercially available kits from Siemens (Washington, DC, USA) following a previously validated protocol [57]. T was run in one batch (so there is not inter-assay coefficient of variation 
$[\mathrm{CV}]$ ), and the intra-assay CVs were $3.16 \%$ and $12.83 \%$ at high and low levels of $T$, respectively.

\section{Procedure}

All participants completed their baseline ImPACT session in the laboratory between August and October of their first year at the university. Sessions occurred between 12 PM and 7 PM to minimize the large fluctuations in $\mathrm{T}$ levels occurring during the morning [51,58] but still provide a workable testing window. The participants were instructed to refrain from eating, drinking (besides water), smoking, chewing gum, or brushing their teeth for 1 hour prior to testing to avoid contamination of saliva samples. Upon arrival, the participants read and signed an informed consent form. An experimenter provided instructions about completing the online questionnaire and providing saliva samples. The participants were left alone in a private room to complete the study and were compensated with US $\$ 15$ for completion of this baseline session.

\section{Statistical Analyses}

Three participants had T levels over 3 SD from the mean, and these participants were removed from analyses. To determine associations between $\mathrm{T}$ and safer sex measures, we conducted Pearson correlations and multiple linear regressions. As noted, analyses with the MCAS subscales included only individuals who had engaged in sexual intercourse.

\section{Main Outcome Measures}

The main outcome measures in this study were $T$ as measured via saliva and safer sex behaviorally relevant attitudes as measured via a composite of three behavioral indices and scores on the short form of the MCAS $[13,49]$.

\section{Results}

\section{Internal Consistency and Validity of the Safer Sex Likelihood Composite}

The internal consistency of the three items included in the safer sex likelihood scale was fairly low, Cronbach's alpha $=0.48$. However, as evidence for convergent validity, the safer sex likelihood score was significantly positively correlated with safer sex resilience, $r(34)=0.53, P=0.001$, and significantly negatively correlated with nicotine use, $r(75)=-0.23, P=0.05$.
Table 1 Correlations between testosterone and safer sex variables

\begin{tabular}{ll}
\hline & $\begin{array}{l}\text { Correlation with } \\
\text { testosterone }\end{array}$ \\
\hline Safer sex likelihood $_{\text {Safer sex resilience }}^{\dagger}$ & $r(73)=0.33^{*}$ \\
Purchase comfort $^{\dagger}$ & $r(32)=0.36^{*}$ \\
Pleasure $^{\dagger}$ & $r(32)=0.37^{\star}$ \\
Effectiveness $^{\dagger}$ & $r(31)=0.31^{\wedge}$ \\
Identity stigma $^{\dagger}$ & $r(31)=-0.17$ \\
Negotiation $^{\dagger}$ & $r(32)=0.08$ \\
\hline
\end{tabular}

${ }^{*} P<0.05, \wedge$ Trend at $P<0.10$

${ }^{\dagger}$ Analyses conducted only with individuals who had ever engaged in sexual intercourse

\section{Safer Sex Likelihood and Resilience}

Correlations between $\mathrm{T}$ and safer sex variables are displayed in Table 1. A significant positive correlation was observed between $\mathrm{T}$ and safer sex likelihood, $r(73)=0.33, P=0.003$, indicating that men with higher $T$ were more likely to engage in safer sex behaviors. Based on previous research, factors that are related to or that might affect associations between $T$ and risk-taking include ever having had intercourse, sexual frequency, and relationship status $[13,50]$. We controlled for these variables using a multiple regression with $\mathrm{T}$ and the control variables as predictors and safer sex likelihood as the dependent variable. The model accounted for $21.4 \%$ of the variation in safer sex likelihood $\left(R_{\text {adj }}^{2}=0.153\right), F(5,65)=3.54, P=0.007$. Among the predictor variables, $\mathrm{T}$ was the strongest and only significant predictor of safer sex likelihood, $\beta=0.03, t(65)=3.10, P=0.003$ (see Table 2). The correlation between $\mathrm{T}$ and safer sex likelihood was especially strong among only those men with sexual experience, $r(32)=0.45, P=0.008$.

Similarly, a significant positive correlation was observed between $\mathrm{T}$ and safer sex resilience in sexually active men, $r(32)=0.36, P=0.037$, indicating that men with higher $\mathrm{T}$ were more likely to follow through with condom use in the face of barriers to doing so. Controlling for sexual fre-

Table 2 Results of a multiple regression predicting safer sex likelihood from testosterone and control variables

\begin{tabular}{lrrr}
\hline & $\beta$ (standard error) & $t$ value & $P$ value \\
\hline Ever had intercourse & $-0.68(0.46)$ & -1.47 & 0.147 \\
Sexual frequency & $-0.17(0.17)$ & -0.99 & 0.326 \\
Relationship status 1 & $0.05(0.37)$ & 0.13 & 0.899 \\
Relationship status 2 & $-0.22(0.15)$ & -1.46 & 0.148 \\
Testosterone & $0.03(0.01)$ & 3.10 & 0.003 \\
\hline
\end{tabular}

Sexual frequency = frequency of partnered sexual activity in the past week. The categorical variable of relationship status was represented as two contrast codes in the regression 
Table 3 Results of a multiple regression predicting safer sex resilience from testosterone and control variables in sexually experienced men

\begin{tabular}{lcrl}
\hline & $\beta$ (standard error) & $t$ value & $P$ value \\
\hline Sexual frequency & $0.18(0.54)$ & 0.34 & 0.738 \\
Relationship status 1 & $1.35(1.39)$ & 0.97 & 0.340 \\
Relationship status 2 & $-0.28(0.61)$ & -0.45 & 0.658 \\
Testosterone & $0.08(0.04)$ & 2.07 & 0.049 \\
\hline
\end{tabular}

Sexual frequency = frequency of partnered sexual activity in the past week The categorical variable of relationship status was represented as two contrast codes in the regression

quency and relationship status in a multiple regression with $\mathrm{T}$ and the control variables as predictors and safer sex resilience as the dependent variable did not change this pattern. The model accounted for $20.0 \%$ of the variation in safer sex resilience $\left(R_{\text {adj }}^{2}=0.081\right), \quad F(4,27)=1.68, \quad P=$ 0.183 . $T$ was the strongest and only significant predictor of safer sex resilience, $\beta=0.081$, $t(27)=2.07, P=0.049$ (see Table 3 ).

\section{Remaining MCAS Subscales}

Here, we considered whether $\mathrm{T}$ was also related to safer sex attitudes and affect. $T$ and purchase comfort were significantly correlated, $r(32)=0.37$, $P=0.031$, indicating that men with higher $\mathrm{T}$ reported more comfort with purchasing condoms. There was a trend for a statistical correlation between $\mathrm{T}$ and pleasure, $r(31)=0.31, P=0.085$, indicating that men with higher $\mathrm{T}$ reported that condoms were less likely to interfere with sexual pleasure. T was not significantly correlated with the other MCAS subscales. Controlling for relationship status and sexual frequency using multiple regression reduced the association between $\mathrm{T}$ and purchase comfort to a trend and made the trend for $\mathrm{T}$ and pleasure nonsignificant. Therefore, $T$ was most strongly associated with safer sex resilience (i.e., safer sex attitudes shown to be relevant to behaviors) rather than safer sex attitudes more generally.

\section{Discussion}

Our results are the first to demonstrate links between higher $\mathrm{T}$ and less sexual risk-taking in terms of attitudes or reported intentions, or less risk-taking in any physical domain. Specifically, we found that men with higher $\mathrm{T}$ report a higher likelihood of engaging in safer sex behaviors and using condoms in the face of barriers to doing so. Yet nonsexual research typically shows the exact opposite, i.e., higher $\mathrm{T}$ is tied to more risk-taking, not less $[24,25,27-29]$ - how can this be?
As most sexual behavior carries risks of STIs, engaging in sexual behavior has been conceptualized as risky, even as some have questioned how "risky" sexual behavior is actually perceived to be [59]. Acquiring STIs has serious health consequences, but individuals often see this possibility as distant and removed relative to the more immediate and personal social consequences of negotiating safer sex [59]. This occurs in the same way that the likelihood of larger risks are underestimated and smaller risks overestimated [60]. Use of condoms can unfortunately lead to negative attributions of individuals who practice safer sex, especially in long-term relationships [12,14,15,17], and these negative attributions can lead to social risk, i.e., harm to reputations and relationships. Navigating safer sex in the face of potential social opprobrium could be socially risky itself, and thus buttressed by psychological constructs such as confidence or boldness.

Confidence or boldness may be related to safer sex in another way. Sexual behavior can convey social status for men [19], such that safer sex behaviors might be a way to demonstrate the frequency of one's sexual activities and the comfort with which one engages in sexually related behaviors. $\mathrm{T}$ has been linked to domains tied to confidence, agency, and status $[23,28]$. Confidence and agency, in turn, may facilitate risk-taking, as is evidenced in studies of financial risk [25]. However, they may also facilitate the avoidance of risk, when doing so can increase or display status. Accordingly, higher $\mathrm{T}$ and safer sex attitudes and intentions might be linked because safer sex represents the "bolder" choice: it might be socially risky or convey social status.

Our results demonstrated that men with higher $\mathrm{T}$ reported more comfort with purchasing condoms. These findings support our interpretation that safer sex implementation may rely on social confidence, as embarrassment is a prime reason that many avoid condom purchase [18]. As with our other findings, this pattern of results cannot be explained by relationship status or sexual frequency since the main correlations were still significant and strong when controlling for these factors. Age also cannot account for our findings since age was restricted such that all but two participants were 18 or 19 years old. Thus, the main finding linking $\mathrm{T}$ and safer sex behaviorally relevant attitudes is robust in the face of at least some relevant confounds.

Our findings demonstrate association rather than directionality. However, sexual situations 
have been shown to increase $T$ [61-64] as have situations that involve status displays [23,28]. As such, it may be that engaging in safer sex behaviors or thinking about safer sex actually increases $\mathrm{T}$ because these behaviors are sexual, involve confidence, or display status. In contrast, higher $\mathrm{T}$ might predict engaging in safer sex behaviors for similar reasons, and there is evidence suggesting that $\mathrm{T}$ can predict future risktaking [25], though most other studies positing this direction of effect have not actually demonstrated causality.

$\mathrm{T}$ was not significantly correlated with the other MCAS condom measures, including negotiation and identity stigma. Research on condom attitudes and intentions clearly demonstrates that safer sex resilience is linked to actual condom use whereas these two measures are not [13]. Some of the other measures, including effectiveness or pleasure, would not be expected to be linked to $T$ given that they tap into more general feelings about condoms rather than behavioral intentions. Overall, the small but significant effect sizes indicate that other non- $T$ social factors likely play a large role even as $\mathrm{T}$ and sexual risk-taking are meaningfully linked. The results indicate that higher $\mathrm{T}$ is associated with more safer sex behaviorally relevant attitudes, which we interpret such that $\mathrm{T}$ is linked to less physical risk (i.e., lower STI risk due to high condom use) but more social risk (i.e., possible stigmatization associated with condom use) or status display (i.e., status afforded to display of sexual activity). The impact of our findings is also, however, to highlight that "sexual risk" may characterize behaviors and attitudes that are protective against STIs, since these behaviors and attitudes are linked with higher $\mathrm{T}$.

Our study is not without limitations. In particular, the safer sex likelihood composite is not a validated measure, and its internal consistency was fairly low. However, the safer sex likelihood scale was created based on factors shown to be important for STI protection [44-48], and its convergence with relevant measures (e.g., the MCAS safer sex resilience scale) points to its value as a meaningful measure of safer sex attitudes. The college-aged men in our sample were fairly sexually inexperienced overall, mainly identified as heterosexual, and generally came from high-income backgrounds; thus, the extent to which our findings generalize to college-aged men, much less other men, is unknown. Finally, future research is needed to determine the extent to which our find- ings linking $T$ to behaviorally relevant safer sex attitudes extend to other safer sex outcomes (e.g., frequency of condom use).

Future studies should attempt to determine whether similar associations between $\mathrm{T}$ and safer sex behaviors and attitudes persist in those contexts where sexual stigma is lessened. It may be that safer sex is especially "risky" for college-aged straight-identified men or sexually inexperienced men compared with older and/or sexual minority men; alternatively, safer sex might be more of an expression of confidence or social status for college-aged men who are newer to sexual activity and eager to establish some set of sexual/social credentials. Future studies should also assess contexts for sexual risk-taking to understand when safer sex might actually be perceived or experienced as the more socially risky choice than failing to practice safer sex. These contexts are likely to differ by community and other factors such as gender, where individuals experience higher or lower levels of stigma attached to safer sex behaviors. Of course, it remains to be shown using meditational analyses that confidence and/or boldness statistically mediates the association between $\mathrm{T}$ and safer sex attitudes as other variables may also or alternatively be at play. Interventions for preventing STIs may benefit from structuring communications in ways that address the social riskiness or status displays of safer sex behaviors, and therefore the interpersonal boldness of safer sex practice.

\section{Conclusions}

Given the robust and repeated correlations between $T$ and behaviorally relevant safer sex attitudes, we conclude that our results suggest that safer sex might be paradoxically perceived as a "bold" or "risky" choice even as it decreases STI risk. Accordingly, risk may be misconstrued in the sexual health arena.

\section{Acknowledgments}

Katherine L. Goldey was supported by a Graduate Research Fellowship from the National Science Foundation (grant no. DGE 0718128). We would like to thank Jose Bauermeister, Nicholas Caverly, Dennis Fortenberry, Patty Kuo, Dario Maestripieri, and Steven Stanton for helpful comments on an earlier draft of this article.

Corresponding Author: Sari M. van Anders, $\mathrm{PhD}$, Departments of Psychology \& Women's Studies, Uni- 
versity of Michigan, 530 Church Street, Ann Arbor, MI 48109, USA. Tel: (1) 734-647-6981; Fax: (1) 734-7643520; E-mail: smva@umich.edu

Conflict of Interest: None.

\section{Statement of Authorship}

\section{Category I}

(a) Conception and Design

Sari van Anders; Terri Conley; Divya Patel

(b) Acquisition of Data

Sari van Anders; Terri Conley; Divya Patel; Katherine Goldey

(c) Analysis and Interpretation of Data Sari van Anders; Katherine Goldey; Daniel Snipes

\section{Category 2}

(a) Drafting the Article Sari van Anders; Katherine Goldey

(b) Revising It for Intellectual Content Sari van Anders; Katherine Goldey; Daniel Snipes; Terri Conley; Divya Patel

\section{Category 3}

(a) Final Approval of the Completed Article Sari van Anders; Katherine Goldey; Daniel Snipes; Terri Conley; Divya Patel

\section{References}

1 Tetrault JM, Fiellin DA, Niccolai LM, Sullivan LE. Substance use in patients with sexually transmitted infections: Results from a national U.S. survey. Am J Addict 2010;19:504-9.

2 Seth P, Wingood GM, DiClemente RJ, Robinson LS. Alcohol use as a marker for risky sexual behaviors and biologically confirmed sexually transmitted infections among young adult African-American women. Womens Health Issues 2011;21: $130-5$.

3 Vivancos R, Abubakar I, Hunter PR. Sex, drugs and sexually transmitted infections in British university students. Int J STD AIDS 2008;19:370-7.

4 Halpern CT, Udry JR, Campbell B, Suchindran C, Mason GA. Testosterone and religiosity as predictors of sexual attitudes and activity among adolescent males: A biosocial model. J Biosoc Sci 1994;26:217-34.

5 Halpern CT, Udry JR, Suchindran C. Testosterone predicts initiation of coitus in adolescent females. Psychosom Med 1997;59:161-71.

6 Halpern CT, Udry JR, Suchindran C. Monthly measures of salivary testosterone predict sexual activity in adolescent males. Arch Sex Behav 1998;27:445-65.

7 Booth A, Johnson DR, Granger DA. Testosterone and men's health. J Behav Med 1999;22:1-19.

8 Booth A, Johnson DR, Granger DA. Testosterone and men's depression: The role of social behavior. J Health Soc Behav 1999;40:130-40.

9 Halpern CT, Campbell B, Agnew CR, Thompson V, Udry JR. Associations between stress reactivity and sexual and nonsexual risk taking in young adult human males. Horm Behav 2002;42:387-98.
10 van Anders SM, Watson NV. Social neuroendocrinology: Effects of social contexts and behaviors on sex steroids in humans. Hum Nat 2006;17:212-37.

11 Coates JM, Herbert J. Endogenous steroids and financial risk taking on a London trading floor. Proc Natl Acad Sci U S A 2008;105:6167-72.

12 Baumgartner JN, Lugina H, Johnson L, Nyamhanga T. "Being faithful" in a sexual relationship: Perceptions of Tanzanian adolescents in the context of HIV and pregnancy prevention. AIDS Care 2010;22:1153-8.

13 Conley TD, Collins BE. Differences between condom users and condom nonusers in their multidimensional condom attitudes. J Appl Soc Psychol 2005;35:603-20.

14 Conley TD, Rabinowitz JL. Scripts, close relationships, and symbolic meanings of contraceptives. Pers Relatsh 2004; 11:539-58.

15 Misovich SJ, Fisher JD, Fisher WA. Close relationships and elevated HIV risk behavior: Evidence and possible underlying psychological processes. Rev Gen Psychol 1997;1:72-107.

16 Coleman LM, Ingham R. Exploring young people's difficulties in talking about contraception: How can we encourage more discussion between partners? Health Educ Res 1999;14:741-50.

17 Hillier L, Harrison L, Warr D. "When you carry condoms all the boys think you want it": Negotiating competing discourses about safe sex. J Adolesc 1998;21:15-29.

18 Bell J. Why embarrassment inhibits the acquisition and use of condoms: A qualitative approach to understanding risky sexual behaviour. J Adolesc 2009;32:379-91.

19 Crawford M, Popp D. Sexual double standards: A review and methodological critique of two decades of research. J Sex Res 2003;40:13-26.

20 MacDonald NE, Wells GA, Fisher WA, Warren WK, King MA, Doherty JA, Bowie WR. High-risk STD/HIV behavior among college students. JAMA 1990;263:3155-9.

21 Baele J, Dusseldorp E, Maes S. Condom use self-efficacy: Effect on intended and actual condom use in adolescents. J Adolesc Health 2001;28:421-31.

22 Holland KJ, French SE. Condom negotiation strategy use and effectiveness among college students. J Sex Res 2011 Jul 6 [Epub ahead of print] doi: 10.1080/00224499.2011.568128.

23 Carney DR, Cuddy AJC, Yap AJ. Power posing: Brief nonverbal displays affect neuroendocrine levels and risk tolerance. Psychol Sci 2010;20:1-6.

24 Vermeersch H, T'Sjoen G, Kaufman JM, Vincke J. The role of testosterone in aggressive and non-aggressive risk-taking in adolescent boys. Horm Behav 2008;53:463-71.

25 Sapienza P, Zingales L, Maestripieri D. Gender differences in financial risk aversion and career choices are affected by testosterone. Proc Natl Acad Sci U S A 2009;106:15268-73.

26 Goudriaan AE, Lapauw B, Ruige J, Feyen E, Kaufman JM, Brand M, Vingerhoets G. The influence of high-normal testosterone levels on risk-taking in healthy males in a 1-week letrozole administration study. Psychoneuroendocrinology 2010;35:1416-21.

27 Vermeersch H, T'Sjoen G, Kaufman JM, Vincke J, Van Houtte $M$. Testosterone, androgen receptor gene CAG repeat length, mood and behaviour in adolescent males. Eur J Endocrinol 2010;163:319-28.

28 Ronay R, von Hippel W. The presence of an attractive woman elevates testosterone and physical risk taking in young men. Soc Psychol Personal Sci 2010;1:57-64.

29 Stanton SJ, Liening SH, Schultheiss OC. Testosterone is positively associated with risk taking in the Iowa Gambling Task. Horm Behav 2011;59:252-6.

30 Booth A, Johnson DR, Granger DA, Crouter AC, McHale S. Testosterone and child and adolescent adjustment: The moderating role of parent-child relationships. Dev Psychol 2003;39:85-98. 
31 Takahashi T, Sakaguchi K, Oki M, Homma S, Hasegawa T. Testosterone levels and discounting delayed monetary gains and losses in male humans. Neuro Endocrinol Lett 2006;27: $439-44$.

32 Vermeersch H, T'Sjoen G, Kaufman JM, Vincke J. Estradiol, testosterone, differential association and aggressive and nonaggressive risk-taking in adolescent girls. Psychoneuroendocrinology 2008;33:897-908.

33 Zethraeus N, Kocoska-Maras L, Ellingsen T, von Schoultz B, Hirschberg AL, Johannesson M. A randomized trial of the effect of estrogen and testosterone on economic behavior. Proc Natl Acad Sci U S A 2009;106:6535-8.

34 Stanton SJ, Mullette-Gillman OA, McLaurin RE, Kuhn CM, LaBar KS, Platt ML, Huettel SA. Low- and high-testosterone individuals exhibit decreased aversion to economic risk. Psychol Sci 2011;22:447-53.

35 Coates JM, Gurnell M, Sarnyai Z. From molecule to market: Steroid hormones and financial risk-taking. Philos Trans R Soc Lond B Biol Sci 2010;365:331-43.

36 Gerra G, Avanzini P, Zaimovic A, Sartori R, Bocchi C, Timpano M, Zambelli U, Delsignore R, Gardini F, Talarico E, Brambilla F. Neurotransmitters, neuroendocrine correlates of sensation-seeking temperament in normal humans. Neuropsychobiology 1999;39:207-13.

37 Coccaro EF, Beresford B, Minar P, Kaskow J, Geracioti T. CSF testosterone: Relationship to aggression, impulsivity, and venturesomeness in adult males with personality disorder. J Psychiatr Res 2007;41:488-92.

38 Campbell BC, Dreber A, Apicella CL, Eisenberg DT, Gray PB, Little AC, Garcia JR, Zamore RS, Lum JK. Testosterone exposure, dopaminergic reward, and sensation-seeking in young men. Physiol Behav 2010;99:451-6.

39 Hermans EJ, Putman P, Baas JM, Koppeschaar HP, van Honk J. A single administration of testosterone reduces fearpotentiated startle in humans. Biol Psychiatry 2006;59:872-4.

40 van Honk J, Schutter DJ, Hermans EJ, Putman P, Tuiten A, Koppeschaar H. Testosterone shifts the balance between sensitivity for punishment and reward in healthy young women. Psychoneuroendocrinology 2004;29:937-43.

41 Schneider G, Nienhaus K, Gromoll J, Heuft G, Nieschlag E, Zitzmann M. Sex hormone levels, genetic androgen receptor polymorphism, and anxiety in $>/=50$-year-old males. J Sex Med 2011 Aug 24 [Epub ahead of print] doi: 10.1111/j.17436109.2011.02443.x.

42 Ljubojevic S, Lipozencic J. Sexually transmitted infections and adolescence. Acta Dermatovenerol Croat 2010;18:305-10.

43 Centers for Disease Control and Prevention. Sexually transmitted disease surveillance 2009. Department of Health and Human Services: Atlanta, GA; 2010.

44 Conley TD, Collins BE. Gender, relationship status, and stereotyping about sexual risk. Pers Soc Psychol Bull 2002; 28:1483-94.

45 Kalichman SC, Cain D. The relationship between indicators of sexual compulsivity and high risk sexual practices among men and women receiving services from a sexually transmitted infection clinic. J Sex Res 2004;41:235-41.

46 Seth P, Wingood GM, Robinson LS, Diclemente RJ. Exposure to high-risk genital human papillomavirus and its association with risky sexual practices and laboratoryconfirmed chlamydia among African-American women. Womens Health Issues 2009;19:344-51.

47 Sheeran P, Orbell S. Do intentions predict condom use? Metaanalysis and examination of six moderator variables. Br J Soc Psychol 1998;37:231-50.

48 Sayles JN, Pettifor A, Wong MD, MacPhail C, Lee S, Hendriksen E, Rees HV, Coates T. Factors associated with selfefficacy for condom use and sexual negotiation among South African youth. J Acquir Immune Defic Syndr 2006; 43:22633.

49 Helweg-Larsen M, Collins BE. The UCLA Multidimensional Condom Attitudes Scale: Documenting the complex determinants of condom use in college students. Health Psychol 1994;13:224-37.

50 van Anders SM, Goldey KL. Testosterone and partnering are linked via relationship status for women and "relationship orientation" for men. Horm Behav 2010;58:820-6.

51 Khan-Dawood FS, Choe JK, Dawood MY. Salivary and plasma bound and "free" testosterone in men and women. Obstet Gynecol 1984;148:441-5.

52 Magrini G, Chiodoni G, Rey F, Felber JP. Further evidence for the usefulness of the salivary testosterone radioimmunoassay in the assessment of androgenicity in man in basal and stimulated conditions. Horm Res 1986;23:65-73.

53 Swinkels LM, Meulenberg PM, Ross HA, Benraad TJ. Salivary and plasma free testosterone and androstenedione levels in women using oral contraceptives containing desogestrel or levonorgestrel. Ann Clin Biochem 1988;25:354-9.

54 Granger DA, Shirtcliff EA, Booth A, Kivlighan KT, Schwartz EB. The "trouble" with salivary testosterone. Psychoneuroendocrinology 2004;29:1229-40.

55 Shirtcliff EA, Granger DA, Likos A. Gender differences in the validity of testosterone measured in saliva by immunoassay. Horm Behav 2002;42:62-9.

56 Quissell DO. Steroid hormone analysis in human saliva. Ann N Y Acad Sci 1993;694:143-5.

57 Campbell KL, Schultheiss OC, McClelland DC. A necessary adjustment of protocol for use of DPC coat-a-count total testosterone assay with saliva. Clin Biochem 1999;32:83-5.

58 Axelsson J, Ingre $M$, Akerstedt T, Holmback U. Effects of acutely displaced sleep on testosterone. J Clin Endocrinol Metab 2005;90:4530-5.

59 Pinkerton SD, Abramson PR. Is risky sex rational? J Sex Res 1992;29:561-8

60 Symons D. How risky is risky sex? J Sex Res 1993;30:188-91.

61 Hellhammer DH, Hubert W, Schurmeyer T. Changes in saliva testosterone after psychological stimulation in men. Psychoneuroendocrinology 1985;10:77-81.

62 Dabbs JM Jr, Mohammed S. Male and female salivary testosterone concentrations before and after sexual activity. Physiol Behav 1992;52:195-7.

63 van Anders SM, Hamilton LD, Schmidt N, Watson NV. Associations between testosterone secretion and sexual activity in women. Horm Behav 2007;51:477-82.

64 Goldey KL, van Anders SM. Sexy thoughts: Effects of sexual cognitions on testosterone, cortisol, and arousal in women. Horm Behav 2011;59:754-64. 